\title{
Comparison of the Vcheck and IMMULITE 2000 methods for T4 measurement in canine and feline serum
}

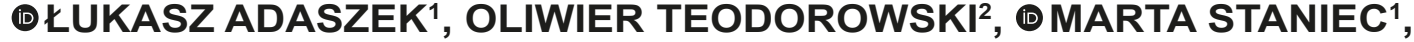 \\ (1) RADOS $\nvdash A W$ JANECKI ${ }^{1}$, NATALIA JACKOWSKA-PEJKO ${ }^{3}$, (B) BANU DOKUZEYLÜL ${ }^{4}$, \\ DSTANIS $Ł A W$ WINIARCZYK ${ }^{1}$, MAŁGORZATA RUTKOWSKA-SZULCZYK ${ }^{3}$
}

\author{
${ }^{1}$ Department of Epizootiology and Clinic of Infectious Diseases, Faculty of Veterinary Medicine, \\ University of Life Sciences in Lublin, Głęboka 30, 20-612 Lublin, Poland \\ ${ }^{2}$ Klinika Teodorowscy, Żwirki i Wigury 5, 43-190 Mikołów, Poland \\ ${ }^{3}$ Vet Planet Sp. z 0.0., 05-092 Łomianki, Poland
}

${ }^{4}$ Department of Internal Medicine, Faculty of Veterinary Medicine, Istanbul University-Cerrahpasa, Avcilar, Istanbul, Turkey

Adaszek Ł., Teodorowski O., Staniec M., Janecki R., Jackowska-Pejko N., Dokuzeylül B., Winiarczyk S., Rutkowska-Szulczyk M.

Comparison of the Vcheck and IMMULITE 2000 methods for T4 measurement in canine and feline serum

\section{Summary}

The aim of this study was to compare canine and feline thyroxine (T4) results obtained by the Vcheck method with those obtained by the IMMULITE 2000 immunoassay, which had previously been validated for canine serum. The concentration of $\mathrm{T} 4$ in 53 canine and 44 feline serum samples was determined concurrently by the Vcheck and IMMULITE methods, the latter as the reference method. The T4 values were compared using the IMMULITE Youden plot and Deming regression analysis. According to the regression analysis, the two methods gave comparable results. Spearman's correlation shows a very high consistency of the results obtained by the two analyzers. The results of the Vcheck method were comparable to those of the IMMULITE 2000 reference method, so Vcheck may be used as an alternative assay to evaluate the serum thyroxine concentration in dogs and cats for the diagnosis of thyroid gland disease.

Keywords: thyroxine, dog, cat, immunoassay

Thyroid hormones affect numerous metabolic processes, and their deficiency may cause a variety of clinical signs, none of which are pathognomonic of the disease. The diagnosis of thyroid diseases is ideally based on a combination of signs and history, along with the results of a physical examination and clinicopathologic testing $(7,11)$. Measurement of serum concentrations of thyroid hormones can be affected by many extrathyroidal factors, and accurate determination of thyroid function in patients with nonthyroidal disease remains a dilemma for many clinicians (6). In veterinary practice, serum total thyroxine (T4) concentration has been commonly used to screen for hypothyroidism and hyperthyroidism in dogs and cats suspected of having these diseases.

Canine hypothyroidism is a common endocrinopathy caused by decreased production of the thyroid hormone. Feline hyperthyroidism is the most common form of endocrinopathy in older cats. The prevalence of feline hyperthyroidism has steadily increased worldwide since the first reports, and the disease is now diagnosed in 1.5-11.4\% of older cats around the world $(12,20)$. Feline hyperthyroidism is the most common endocrine disorder in middle-aged or older cats in the United States $(2,12)$, where it is found in up to $10 \%$ of cats older than 10 years $(2,12)$.

In human medicine, free T4 and endogenous TSH concentrations are routinely measured, along with total $\mathrm{T} 4$, to assess the thyroid status $(9,14,16)$. Assays for determination of free T4 and endogenous TSH in dogs and cats are now widely available, and the results of several studies confirm the usefulness of these tests in differentiating animals with hypothyroidism or hyperthyroidism from dogs and cats that are euthyroid $(2,4,14)$. Interpretation of the serum T4 concentration is crucial in the diagnosis and management of dogs with both hypothyroidism and hyperthyroidism, and decision levels for thyroid function testing are well established.

As a result, these tests are increasingly popular as tests of choice for the diagnosis of hypothyroidism and hyperthyroidism. In one study, Peterson et al. (14) 
found the free $\mathrm{T} 4$ concentration to be the most accurate diagnostic test for dogs with hypothyroidism, whereas determination of the serum TSH concentration alone was of less value.

Many studies have been undertaken to validate analyzers for the T4 concentration in dogs and cats $(10,13,21)$. IMMULITE 2000 is an immunoassay analyzer that has been validated for the measurement of the serum T4 concentration in dogs. The assay is considered to be specific and free of interference (15). Vcheck is a compact, rapid, automated immunoassay analyzer that needs calibrating only once every 14 days, optimizing the cost per result (1). While IMMULITE 2000 is usually applicable only in specially equipped laboratories, Vcheck is cheaper and well suited for routine work. The Vcheck T4 test is an enzyme-linked fluorescent assay designed for the Vcheck system. The aim of this study was to compare the Vcheck assay with the IMMULITE 2000 immunoassay for the measurement of the canine and feline serum $\mathrm{T} 4$ concentration.

\section{Material and methods}

Non-fasting blood samples were obtained from the cephalic vein of 53 canine patients (group 1) and 44 feline patients (group 2) referred to the clinic for a prophylactic check of their health status. The dogs in group 1 included 31 males and 22 females of different breeds, and ranged from 2- to 15-year-olds, while the cats in group 2 included 17 males and 27 females of different breeds, and ranged from 2- to 17-year-olds. Selection was based on the serum $\mathrm{T} 4$ concentration to represent the entire working range of IMMULITE 2000.

The T4 concentration values for dogs were interpreted as follows: a) T4 concentration value $<1.00 \mu \mathrm{g} / \mathrm{dl}$ suggests hypothyroidism, b) T4 concentration $=1-4.0 \mu \mathrm{g} / \mathrm{dl}-$ physiological value, c) T4 concentration $>4.0 \mu \mathrm{g} / \mathrm{dl}$ suggests hyperthyroidism. The feline T4 concentration values were interpreted as follows: a) T4 concentration value $<0.8 \mu \mathrm{g} / \mathrm{dl}$ suggests hypothyroidism, b) T4 concentration $=0.8-4.7 \mu \mathrm{g} / \mathrm{dl}$ - physiological value, c) T4 concentration $>4.7 \mu \mathrm{g} / \mathrm{dl}$ suggests hyperthyroidism (21). Blood samples were collected into Vacuette Tubes. The samples were immediately centrifuged, and serum was removed. The T4 concentration was measured with an IMMULITE 2000 analyzer (Siemens Healthcare Diagnostics, Deerfield, IL, USA), which uses a solid-phase competitive enzyme-amplified chemiluminescent immunoassay. This assay was used as the reference method in the study. It has a limit of detection of $0.199 \mu \mathrm{g} / \mathrm{dl}$ $(5.5 \mathrm{nmol} / \mathrm{L})$ and a calibration (working) range of 0.725 $-50.02 \mu \mathrm{g} / \mathrm{dl}(20-1380 \mathrm{nmol} / \mathrm{L})(15,18)$. T4 concentrations were concurrently determined using the Vcheck assay, an automated test for the quantitative determination of thtroxine in canine and feline serum (Vetexpert). Both analyzers were cleaned, calibrated, and operated in accordance with the manufacturer's instructions.

A paired Student's t-test was used to test for significant differences between $\mathrm{T} 4$ results obtained by the Vcheck analyzer and the IMMULITE 2000. Differences were considered statistically significant at $\mathrm{p}<0.05$. The T4 values were compared using Youden plot and Deming regression analysis. Statistica 10.0 PL software was used for the calculations.

\section{Results and discussion}

T4 concentrations in the serum of dogs from group 1 analyzed by IMMULITE 2000 were normal (1.07-3.84 $\mu \mathrm{g} / \mathrm{dl}$, range $1-4 \mu \mathrm{g} / \mathrm{dl})$ in 32 samples, higher than normal (4.10-5.02 $\mu \mathrm{g} / \mathrm{dl}$, range $>4 \mu \mathrm{g} / \mathrm{dl})$ in 9 samples, and lower than normal $(0.5-0.96 \mu \mathrm{g} / \mathrm{dl}$, range $<1 \mu \mathrm{g} / \mathrm{dl})$ in 12 samples. Examination of the same serum samples by the Vcheck analyzer showed that the T4 concentration was normal $(1.05-3.99 \mu \mathrm{g} / \mathrm{dl})$ in 34 samples, higher than normal (4.05-5.97 $\mu \mathrm{g} / \mathrm{dl})$ in 5 samples, and lower than normal $(0.5-0.9 \mu \mathrm{g} / \mathrm{dl})$ in 14 samples.

For three samples in which the IMMULITE 2000 analysis showed decreased T4 concentrations $(0.94$, $0.94,0.96 \mu \mathrm{g} / \mathrm{dl})$, the results obtained by Vcheck were within the reference norm $(1.06,1.11,1.35 \mu \mathrm{g} / \mathrm{dl})$. For six samples in which the IMMULITE 2000 analysis showed normal T4 concentrations $(1.07,1.10,1.19$, $1.22,1.28,1.13 \mu \mathrm{g} / \mathrm{dl})$, the results obtained by Vcheck were below normal $(0.62,0.69,0.77,0.83,0.87 \mu \mathrm{g} / \mathrm{dl})$, and for one with a normal T4 concentration value according to the IMMULITE 2000 analyzer $(3.22 \mu \mathrm{g} / \mathrm{dl})$, the results obtained by Vcheck were elevated $(4.05 \mu \mathrm{g} /$ dl). For five samples in which the IMMULITE 2000 analysis showed elevated T4 concentrations (4.10, $4.15,4.17,4.24,4.65 \mu \mathrm{g} / \mathrm{dl})$, the results obtained by Vcheck were within the normal range $(3.16,3.17,3.43$, $3.44,3.99 \mu \mathrm{g} / \mathrm{dl})$.

$\mathrm{T} 4$ concentrations in the serum of cats from group 2 analyzed by IMMULITE 2000 , were normal (0.8$-4.15 \mu \mathrm{g} / \mathrm{dl}$, range $0.8-4.7 \mu \mathrm{g} / \mathrm{dl}$ ) in 31 samples, higher than normal $(5.15-15 \mu \mathrm{g} / \mathrm{dl}$, range $>4.7 \mu \mathrm{g} / \mathrm{dl})$ in 10 samples, and lower than normal $(0.58-0.77 \mu \mathrm{g} / \mathrm{dl}$, range $<0.8 \mu \mathrm{g} / \mathrm{dl}$ ) in 3 samples. Examination of the same serum samples by the Vcheck analyzer showed that T4 concentrations were normal $(0.84-3.53 \mu \mathrm{g} / \mathrm{dl})$ in 31 samples, higher than normal $(5.37-8 \mu \mathrm{g} / \mathrm{dl})$ in 11 samples, and lower than normal $(0.58-0.76 \mu \mathrm{g} / \mathrm{dl})$ in 2 samples.

For one sample in which the IMMULITE 2000 analysis showed a decreased $\mathrm{T} 4$ concentration $(0.77$ $\mu \mathrm{g} / \mathrm{dl})$, the result obtained by Vcheck was within the reference norm $(1.16, \mu \mathrm{g} / \mathrm{dl})$. For another sample, in which the IMMULITE 2000 analysis showed a normal T4 concentration $(4.15 \mu \mathrm{g} / \mathrm{dl})$, the result obtained by Vcheck was above the norm $(5.51 \mu \mathrm{g} / \mathrm{dl})$.

The mean T4 concentration for all samples was $37.84 \mu \mathrm{g} / \mathrm{dl}$ according to IMMULITE 2000 and $34.71 \mu \mathrm{g} / \mathrm{dl}$ according to Vcheck (Tab. 1).

Tab. 1. Comparison of results obtained by the Vcheck and IMMULITE 2000 methods for $\mathrm{T} 4$ serum determination

\begin{tabular}{|l|c|c|c|c|c|c|}
\hline \multicolumn{1}{|c|}{ Method } & Mean & SD & $95 \%$ CI & Median & Min. & Max. \\
\hline IMMUULITE 2000 & 37.84 & 32.09479 & 44.30642 & 31.27 & 6.40 & 193.00 \\
Vcheck & 34.71 & 26.01871 & 39.95116 & 30.89 & 6.40 & 103.00 \\
\hline
\end{tabular}




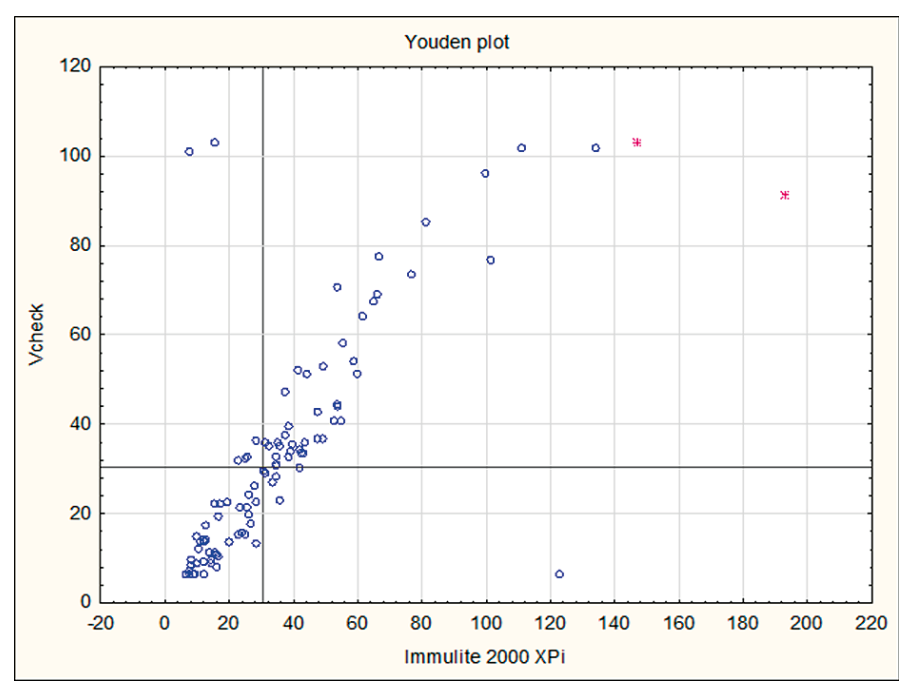

Fig. 1. Comparison between the Vcheck analyzer and the IMMULITE 2000 reference method for T4 serum concentration $(\mu \mathrm{g} / \mathrm{dL})$ in dogs and cats. Youden plot

The results of statistical analysis indicate that $\mathrm{T} 4$ concentrations obtained with the Vcheck analyzer and the IMMULITE 2000 did not differ significantly ( $p>0.0001$, Student's paired t-test). Spearman's correlation shows a very high consistency of the results obtained by the two analyzers (rho $=0.81$ ) (Fig. 1, Fig. 2). The Vcheck analyzer has good specificity for determining $\mathrm{T} 4$ concentrations in feline and canine serum. In this study, there was a strong correlation (rho $=0.81$ ) between $\mathrm{T} 4$ concentrations in feline and canine serum measured by the Vcheck and IMMULITE 2000 methods. The tight-fitting regression line demonstrated that Vcheck had good linearity with IMMULITE 2000 (Fig. 2). Thus, T4 concentrations obtained by the Vcheck and IMMULITE 2000 methods were highly comparable across this range of values.

Validations of the Immulite chemiluminescent T4 assay (Siemens Healthineers USA) have been published for dogs (17) and cats (5). These studies have frequently been cited in other published studies of thyroid function in dogs and cats $(3,8,19)$.

The Vcheck analyzer was easy and fast to operate. The rapidity of measurement (20 minutes), the small sample required $(50 \mu 1)$, and the wide working range, together with its precision, linearity, and comparability to the reference method, make the Vcheck method suitable for canine serum T4 analysis in samples obtained as part of thyroid endocrine function testing.

Rapid and easy-to-use analyzers for the determination of T4 levels in the blood of dogs and cats are becoming increasingly attractive to veterinary clinics, also because of the increasing frequency of in-office diagnosis of hypothyroidism and hyperthyroidism in dogs and cats. Wolff et al. (21) analyzed the utility of the Microgenics DRI TT4 enzyme immunoassay (EIA) designed for use in humans (MTT4; Microgenics Corporation, Fremont, California) in determining T4 levels in dogs and cats. MTT4 assays are commonly

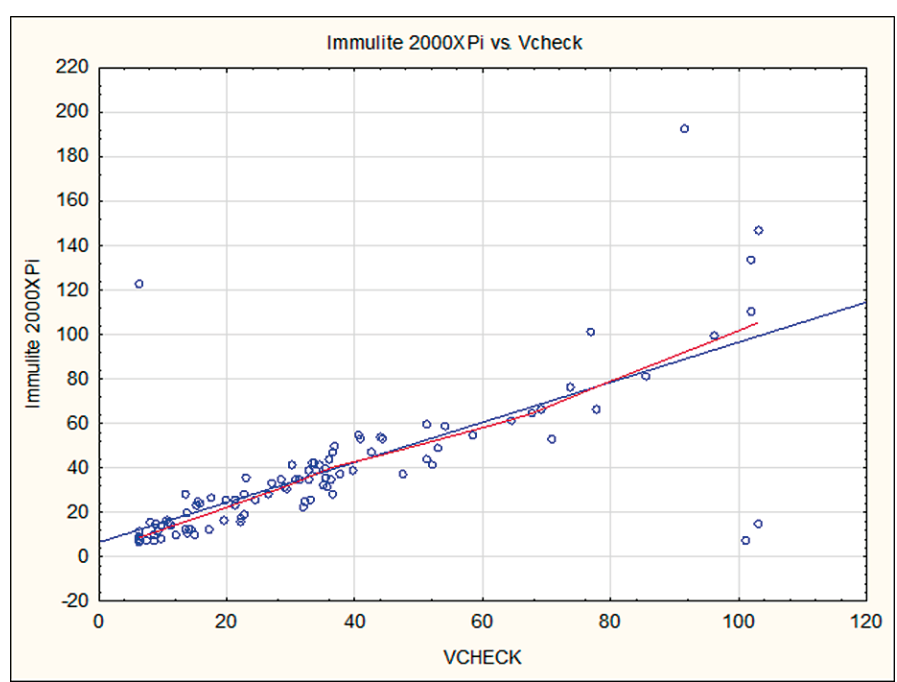

Fig. 2. Comparison between the Vcheck analyzer and the IMMULITE 2000 reference method for T4 serum concentration $(\mu \mathrm{g} / \mathrm{dL})$ in dogs and cats. Demming regression

used in commercial laboratories in the United States. The MTT4 assay has been evaluated for linearity, precision, accuracy, analytical range, and detection limits in healthy animals and in those affected by hypothyroidism or hyperthyroidism, but in most cases this information has not been published in the peer-reviewed literature. Comparison of the $\mathrm{T} 4$ concentration results obtained with IMMULITE with MTT4 results showed a constant bias of $0.14 \mu \mathrm{g} / \mathrm{dL}$ (95\% CI, 0.04-0.22) for dogs and $0.22 \mu \mathrm{g} / \mathrm{dL}(95 \% \mathrm{CI}, 0.09-0.33)$ for cats; proportional bias was $0.76(95 \% \mathrm{CI}, 0.72-0.80)$ for dogs and 0.71 (95\% CI, 0.69-0.74) for cats.

The differences between the IMMULITE and MTT4 results may affect interpretation at higher serum $\mathrm{T} 4$ concentrations. Compared to MTT4, the IMMULITE T4 proportional bias will underestimate serum T4 concentrations in dogs and cats, so serial TT4 measurements should be made using the same assay.

The Vcheck analyzer for determining T4 concentrations in canine serum has good specificity. There was a strong correlation between T4 concentrations in canine serum measured by the Vcheck and IMMULITE methods in this study. The tight-fitting regression line demonstrated that Vcheck had good linearity with IMMULITE. Thus, the T4 concentrations obtained by the Vcheck and IMMULITE-2000 methods were highly comparable in this range of values in the sera of dogs and cats.

Our own observations, as well as literature data, indicate that rapid analyzers are effective in the clinical assessment of thyroid gland function. "Effective" performance means that the method is acceptable if performed by a highly controlled instrument system that is carefully monitored. The authors would like to emphasize that each laboratory must have a reference interval for the thyroid concentration and that caution should be used to determine the cut-off values necessary to differentiate between dogs with and without hypothyroidism or hyperthyroidism. 


\section{References}

1. Adaszek L., Teodorowski O., Staniec M., Janecki R., Jackowska-Pejko N.: Comparison of the Vcheck and IMMULITE 2000 methods for cortisol measurement in canine serum. Med. Weter. 2021, 77, 397-400.

2. Carney H. C., Ward C. R., Bailey S. J., Bruyette D., Dennis S., Ferguson D., Hinc A., Rucinsky A. R.: AAFP Guidelines for the Management of Feline Hyperthyroidism. J. Feline Med. Surg. 2016, 18, 400-416.

3. Diaz-Espineira M. M., Mol J. A., Peeters M. E., Pollak Y. W. E. A., Iversen L., van DijkJ. E., Rijnberk A., Kooistra H. S.: Assessment of thyroid function in dogs with low plasma thyroxine concentration. J. Vet. Intern. Med. 2007, 21, 25-32.

4. Dixon R. M., Mooney C. T.: Evaluation of serum free thyroxine and thyrotropin concentrations in the diagnosis of canine hypothyroidism. J. Small Anim. Pract. 1999, 40, 72-78.

5. Edinboro C. H., Scott-Moncrieff J. C., Janovitz E., Thacker H. L., Glickman L. T.: Epidemiologic study of relationships between consumption of commercial canned food and risk of hyperthyroidism in cats. J. Am. Vet. Med. Assoc. 2004, 224, 879-886.

6. Ferguson D. C.: The effect of nonthyroidal factors on thyroid function tests in dogs. Compend. Contin. Educ. Pract. Vet. 1988, 10, 1365-1377.

7.Ferguson D. C.: Update on diagnosis of canine hypothyroidism. Vet. Clin. North. Am. Small Anim. Pract. 1994, 24, 515-539.

8. Higgs P., Costa M., Freke A., Papasouliotis K.: Measurement of thyroxine and cortisol in canine and feline blood samples using two immunoassay analyzers. J. Small Anim. Pract. 2014, 55, 153-159.

9. MeekJ. C.: Tests of thyroid function: update in the diagnosis and management of thyroid disease. Compr. Ther. 1990, 16, 20-27.

10. Panakova L., Koch H., Kolb S., Mueller R. S.: Thyroid testing in Sloughis. J. Vet. Intern. Med. 2008, 22, 1144-1148.

11. Panciera D. L.: Developing a rational approach to diagnosing and treating canine hypothyroidism. Vet. Med. 1997, 43-57.

12. Peterson M. E.: Hyperthyroidism in cats: what's causing this epidemic of thyroid disease and can we prevent it? J. Feline Med. Surg. 2012, 14, 804-818.
13. Peterson M. E.: More than just T4: diagnostic testing for hyperthyroidism in cats. J. Feline Med. Surg. 2013, 15, 765-777.

14. Peterson M. E., Melian C., Nichols R.: Measurement of serum total thyroxine, triiodothyronine, free thyroxine and thyrotropin concentrations for diagnosis of hypothyroidism in dogs. J. Am. Vet. Med. Assoc. 1997, 211, 1396-1400.

15. Proverbio D., Groppetti D., Spada E., Perego R.: Comparison of the VIDAS and IMMULITE-2000 methods for cortisol measurement in canine serum. Vet. Clin. Pathol. 2009, 38, 332-336.

16. Ramsey I. K., Evans H., Herrtage M. E.: Thyroid-stimulating hormone and total thyroxine concentrations in euthyroid, sick euthyroid and hypothyroid dogs. J. Small Anim. Pract. 1997, 38, 540-545.

17. Scott-Moncrieff J. C., Nelson R. W.: Change in serum thyroid-stimulating hormone concentration in response to administration of thyrotropin-releasing hormone to healthy dogs, hypothyroid dogs, and euthyroid dogs with concurrent disease. J. Am. Vet. Med. Assoc. 1998, 213, 1435-1438.

18. Singh A. K., Jiang Y., White T., Spassova D.: Validation of nonradioactive chemiluminescent immunoassay methods for the analysis of thyroxine and cortisol in blood samples obtained from dogs, cats and horses. J. Vet. Diagn. Invest. 1997, 9, 261-268.

19. Slater M. R., Geller S., Rogers K.: Long-term health and predictors of survival for hyperthyroid cats treated with iodine 131. J. Vet. Intern. Med. 2001, 15, 47-51.

20. Wet C. S. de, Mooney C. T., Thompson P. N., Schoeman J. P.: Prevalence of and risk factors for feline hyperthyroidism in Hong Kong. J. Feline Med. Surg. 2009, 11, 315-321.

21. Wolff E. D. S., Bilbrough G., Moore G., Guptill L., Scott-Moncrieff J. C.: Comparison of 2 assays for measuring serum total thyroxine concentration in dogs and cats. J. Vet. Intern. Med. 2020, 34, 607-615.

Corresponding author: Marta Staniec DVM, PhD, Department of Epizootiology and Clinic of Infectious Diseases, Faculty of Veterinary Medicine, University of Life Sciences in Lublin, Głęboka 30, 20-612 Lublin, Poland; e-mail: marta.staniec@up.lublin.pl 